\title{
Medical Photography: Documentation, Art, and the Expression of Human Emotions
}

\author{
Elisabeth Aberer Werner Stieber Donja Homayoon \\ Regina Fink-Puches Roland Lichen Wolfgang Salmhofer \\ Alexandra Gruber-Wackernagel Werner Aberer \\ Department of Dermatology and Venereology, Medical University of Graz, Graz, Austria
}

\section{Keywords}

Medical photography · Skin · Documentation · Art · Emotion · Disease burden · Quality of life

\begin{abstract}
Medical photography is the state of the art for the documentation of dermatological disease. Experienced photographers take pictures of the most typical skin lesions in order to assist the clinician in assessing disease morphology and activity. In this study, we present 6 individuals with a variety of dermatoses and the expression of the patients' emotions. The patients were asked to show their diseased skin and to present typically involved areas in the respective disease. The feelings expressed by their body movements and positions are viewed and interpreted. The patients' history will be reported retrospectively. The aim of the report is to show that the art of medical photography does not only document skin lesions but also the disease burden and the associated impairment of quality of life. Moreover, dermatologic photography is a sensitive intervention for patients viewed in the light of teaching and patient care.

(C) 2016 The Author(s)

Published by S. Karger AG, Basel
\end{abstract}




\section{Introduction}

The Global Burden of Diseases Study recently showed that skin diseases are the fourth leading cause of a nonfatal disease burden [1]. However, the patients' needs are frequently not identified, and the burden of the skin disease remains neglected or unrecognized [2]. Skin lesions have been described extensively in contrast to the patients' bodily signs. Facial expression and bodily gestures may reveal passions and emotions [3]. Anthropologists have shown that many facial expressions are not unique for a specific culture but are universal [4]. Facial expressions may show features that express emotions such as happiness, sadness, anger, fear, surprise, disgust, or contempt. Cabanac [5] defined emotion as 'any mental experience with high intensity and high hedonic content (pleasure/displeasure)'.

Photography is the state of the art for visual clinical documentation. Leong and Leong [6] have stated that 'a picture speaks a thousand words'. Photographs reduce the misunderstandings that arise from varied descriptive methods. In dermatology, experienced photographers take pictures of the most typical skin lesions and, thus, assist the clinician in assessing disease morphology and activity.

In the present study, we describe a variety of dermatoses in relation to the expression of the patients' emotions that may be noticed as an objective sign, or the expression of the patients' feelings may be perceived on the level of empathy. Six individuals were chosen, and the pictures are shown here. The patients' histories were analyzed retrospectively and reported. The aim of the present study is to draw the attention of physicians and students to the patients' disease burden and impaired quality of life as seen on pictures in order to learn more about the subjective nature of the disease.

\section{Methods}

Photographs were taken after the treating physician had allocated outpatients to the photography unit for routine documentation. The patients had signed a written consent form for this intervention, for disease documentation, teaching, and publication. Patients were selected personally by the photographer based on their existing skin condition. After a conversation about the respective disease, patients were asked whether they wished to express their current emotions on a picture, and they agreed. The study was approved by the ethics committee of the Medical University of Graz (approval No. EK 28-388 ex 15/16).

The patients' medical histories were taken from the electronic database of the University Hospital of Graz (MEDOCS), and the patient data were documented. The pictures were analyzed by an observer and from the dermatological point of view. The emotions presented in the pictures were described after discussion with the authors of the study.

\section{Patients}

\section{Patient 1}

A 41-year-old Russian immigrant with no knowledge of English or German was referred to our hospital with a 3-year history of psoriasis vulgaris (fig. 1). Due to the language barrier, a professional translator was used to register the patient's medical history and communicate with him. Previously, he had been given local treatment (calcipotriol, dithranol, UVB therapy, and various topical corticosteroids) by a resident dermatologist. Owing to progressive psori- 
atic lesions and arthralgia, systemic therapy with ustekinumab was initiated at our institution.

Subjective Symptoms. The intense redness of all body regions, with widespread exfoliative scales on the trunk, extremities, and scalp were very burdensome for the patient. He suffers from massive skin dryness, with tightened skin and intermittent pruritus. Moreover, he complains of painful swelling in the ankle, elbow, and sacroiliac joint. Under ongoing therapy, his disease has improved and seems to be stable at the moment, but his cutaneous disease still causes him severe emotional stress and limitations in his daily life.

\section{Patient 2}

A 54-year-old woman is under regular supervision at our outpatient department, with a long-term history of systemic sclerosis and incipient lung fibrosis (fig. 2). The disease was first diagnosed in 2009. Since then, she has undergone several treatments to prevent disease progression and limitations in her daily life. At the moment, the disease is stable. The patient receives monthly infusions of Prostavasin at the office of her general practitioner, low-dose oral corticosteroids, and extracorporeal photopheresis every 3 months.

Subjective Symptoms. The patient has massively thickened skin, especially on the fingers, hands, décolleté, and upper back, with recurrent finger ulcers and limited mobility. Moreover, she has experienced a loss of facial expression with microstomia, hypopigmentation, and rarefied eyebrows and lashes. She has difficulties in swallowing.

\section{Patient 3}

A 45-year-old man presented to our outpatient clinic with an acute flare of preexisting ichthyosis (Netherton syndrome), with large-scale detachment of the skin (fig. 3). For years, he had been treated with systemic retinoids. Due to exacerbation of the disease, the daily therapy with acitretin was discontinued by the patient. Currently, he is being treated with lipid-balancing and keratinolytic local therapy in the trunk, extremities, hands, and feet.

Subjective Symptoms. He had stinging skin pain, itchiness, and dryness of the skin.

\section{Patient 4}

A 59-year-old man with metastatic lung cancer, first diagnosed in March 2014, was referred to our dermatological emergency department with a papulopustular exanthema due to ongoing treatment with Tarceva (fig. 4). He has a history of skin eruption to another chemotherapeutic agent (Taxotere). His exanthema was treated with local antiseptics and antibiotics.

Subjective Symptoms. Apart from his malignant primary disease, the patient has itchy erythematous lesions in the face and chest, with an inflammatory indurated periorbital skin.

\section{Patient 5}

An 89-year-old woman with multiple age-related diseases but generally in good condition, without any significant limitation in her daily life, was referred by a resident dermatologist for the excision of a squamous cell carcinoma on the forehead (fig. 5). She was admitted to the hospital for surgery and was discharged with a bland surgical wound.

Subjective Symptoms. The woman had no subjective skin complaints due to the ulcerous skin lesion on the forehead. The tumor, a squamous cell carcinoma on histology, had to be removed because it was malignant. 


\section{Patient 6}

A 58-year-old man presented at our outpatient department of dermato-oncology in 2015 with recurrent hyperkeratotic lesions especially on the hands since 2006, primarily diagnosed as psoriasis palmoplantaris (fig. 6). In 2009, he developed erythematous skin lesions on the trunk and extremities, diagnosed as atopic dermatitis. He required several treatment regimens such as methotrexate to relieve the subjective symptoms and pruritus of the erythematous skin. In 2010, the patient received the final diagnosis of mycosis fungoides. He has been treated with extracorporeal phototherapy, PUVA, UVB, systemic immunosuppressive therapies, and retinoids. His personal life and marriage suffered immensely due to his progressive disease, culminating in a divorce. In 2015, at the time this picture was taken, the patient experienced a renewed flare with palmoplantar hyperkeratosis and onychodystrophia and skin lesions on the face, on the forearm, and chest.

Subjective Symptoms. He suffers due to his severe pruritus and scaling of the skin. After taking oral steroids recently, his skin lesions improved. Despite the side effects, he decided not to reduce the dosage of corticosteroids. He is continuing his medication because he wishes to improve his quality of life.

\section{Discussion}

Medical photography has been applied since the birth of the technology in 1840 and is an essential tool for the documentation of skin disease. It has replaced the artistic illustrations that filled old textbooks and atlases [7]. The advantage of photographic imaging is that it reveals actual conditions [8]. Patients are photographed in their actual environment, with the unpleasant facial expression of a sick person, thus also revealing a social image [9].

Initially, photography was a scientific tool rather than a form of artistic expression. But much like a painting, a photograph has the ability to move, engage, and inspire viewers. Fine art photography is a subset of fine art created with a camera [10]. Greenberg [11] declared that 'photography is the most transparent of the art mediums devised or discovered by man'.

The selected photographs of patients in this report may be viewed from the artistic standpoint. This does not only require excellent technical equipment but also skilled personnel. The photographer needs to know about the disease in order to select the appropriate distance, angle, lighting, and background [7]. Errors can be glossed over in artistic photography, but medical photography is objective, and the patients being photographed are authentic.

On the pictures, we see the patients' needs in their current situation as well as their sense of dignity and hope. Hacard et al. [12] studied the patients' perception of medical photography. Concerns about ethical and legal limitations have led to guidelines for the standardization of patient information and consent forms. The modality of using images, financial and legal implications, the quality of medical photography, and its psychological impact were assessed in a questionnaire. Sharing anonymized pictures with others was readily accepted. The highest numbers of nonresponses were noted for questions concerning privacy (29.4\%), feeling uncomfortable (30.5\%), and the need for a more detailed consent form (33.3\%). Lau et al. [13] reported that patients agreed to have their photographs used by treating doctors $(98 \%)$, other doctors $(74 \%)$, for the purpose of teaching students $(82 \%)$, and for patient education (88\%).

Photography, viewed as a medical intervention, may be very challenging for the patient, and the fact may not be realized by physicians. To our knowledge, this aspect has not been 
given sufficient attention in the past. Some patients get anxious, while others are disgusted when they have to get off their clothes and present their diseased body. A disabled person also does not wish to be seen in the public and viewed with pity. Our challenge when treating severely diseased dermatological patients is to understand the emotions they express. The medical workup of the treating physician must include a psychosomatic approach [14].

Emotional impairment can be measured by different questionnaires as subgroups of health-related quality of life questionnaires or in questionnaires measuring depression. However, questionnaires are not able to analyze the heterogeneous background of emotions as shown in our photographs. Patients with a sad facial expression are unfairly labeled as depressive. In nine randomized studies, it was found that the routine administration of psychiatric questionnaires with feedback to clinicians did not improve the detection of emotional disorders or patient outcome, although persons with high scores may benefit from the questionnaires [15]. The realization of this fact did not translate into a higher rate of interventions.

Measuring the expression of emotions is subject to individual differences and is far from being standardized. The most common emotions in disorders of the skin were reported by English [14] in 1949. These were the need for love, anxiety, hostility, inferiority, ambivalence, guilt, ambition, and envy. All of these characteristics have a common source, namely fear of the loss of love and recognition. Different skin diseases were assigned to special emotions.

Photography is the state of the art for the documentation of disease, for teaching, and in science. It is also a means of portraying conditions and movements and visualizing changes. Dermatologic photography, as an intervention, may be a severe psychological challenge for some patients. For others, it might be a means of getting attention and, thus, assist them in coping with the disease. Viewing the pictures of patients helps medical doctors and students to study dermatological diagnoses and also study their patients' emotions and psychological impairment. Therefore, greater attention should be given to the meaning of patients' photography in dermatology.

\section{Statement of Ethics}

All patients signed a written informed consent for the publication of their pictures.

\section{Disclosure Statement}

The authors declare no conflicts of interest.

\section{References}

-1 Hay RJ, Johns NE, Williams HC, Bolliger IW, Dellavalle RP, Margolis DJ, Marks R, Naldi L, Weinstock MA, Wulf SK, et al: The global burden of skin disease in 2010: an analysis of the prevalence and impact of skin conditions. J Invest Dermatol 2014;134:1527-1534.

2 Dalgard FJ, Gieler U, Tomas-Aragones L, Lien L, Poot F, Jemec GB, Misery L, Szabo C, Linder D, Sampogna F, et al: The psychological burden of skin diseases: a cross-sectional multicenter study among dermatological out-patients in 13 European countries. J Invest Dermatol 2015;135:984-991.

-3 Pichel B: From facial expressions to bodily gestures: passions, photography and movement in French 19-century sciences. Hist Human Sci 2016;29:27-48. 
Aberer et al.: Medical Photography: Documentation, Art, and the Expression of Human Emotions

-4 Ragsdale JW, Van Deusen R, Rubio D, Spagnoletti C: Recognizing patients' emotions: teaching health care providers to interpret facial expressions. Acad Med 2016, Epub ahead of print.

5 Cabanac M: What is emotion? Behav Processes 2002;60:69-83.

6 Leong FJ, Leong AS: Digital imaging in pathology: theoretical and practical considerations, and applications. Pathology 2004;36:234-241.

7 Neuse WH, Neumann NJ, Lehmann P, Jansen T, Plewig G: The history of photography in dermatology. Milestones from the roots to the 20th century. Arch Dermatol 1996;132:1492-1498.

8 Hardy MA, de Montméja MA: Clinique photographique de l'hopital Saint-Louis. Paris, Chamerot et Lauwereyns, 1868.

-9 Kuner N, Hartschuh W: Possibilities and limits of early photography in dermatology. The 'Clinique photographique de l'hopital Saint-Louis' von 1868 (in German). Hautarzt 2003;54:760-764.

10 Beck SG: What is fine art photography? http://www.sgbphotography.com/articles/What_Is_Fine_Art_Photography.aspx.

11 Greenberg C: The Collected Essays and Criticism, Volume 2: Arrogant Purpose, 1945-1949. Chicago, University of Chicago Press, 1988.

12 Hacard F, Maruani A, Delaplace M, Caille A, Machet L, Lorette G, Samimi M: Patients' acceptance of medical photography in a French adult and paediatric dermatology department: a questionnaire survey. Br J Dermatol 2013;169:298-305.

13 Lau CK, Schumacher HH, Irwin MS: Patients' perception of medical photography. J Plast Reconstr Aesthet Surg 2010;63:e507-e511.

14 English OS: Role of emotion in disorders of the skin. Arch Dermatol Syphilol 1949;60:1063-1076.

15 Gilbody SM, House AO, Sheldon TA: Routinely administered questionnaires for depression and anxiety: systematic review. BMJ 2001;322:406-409. 


\section{Case Reports in Dermatology}

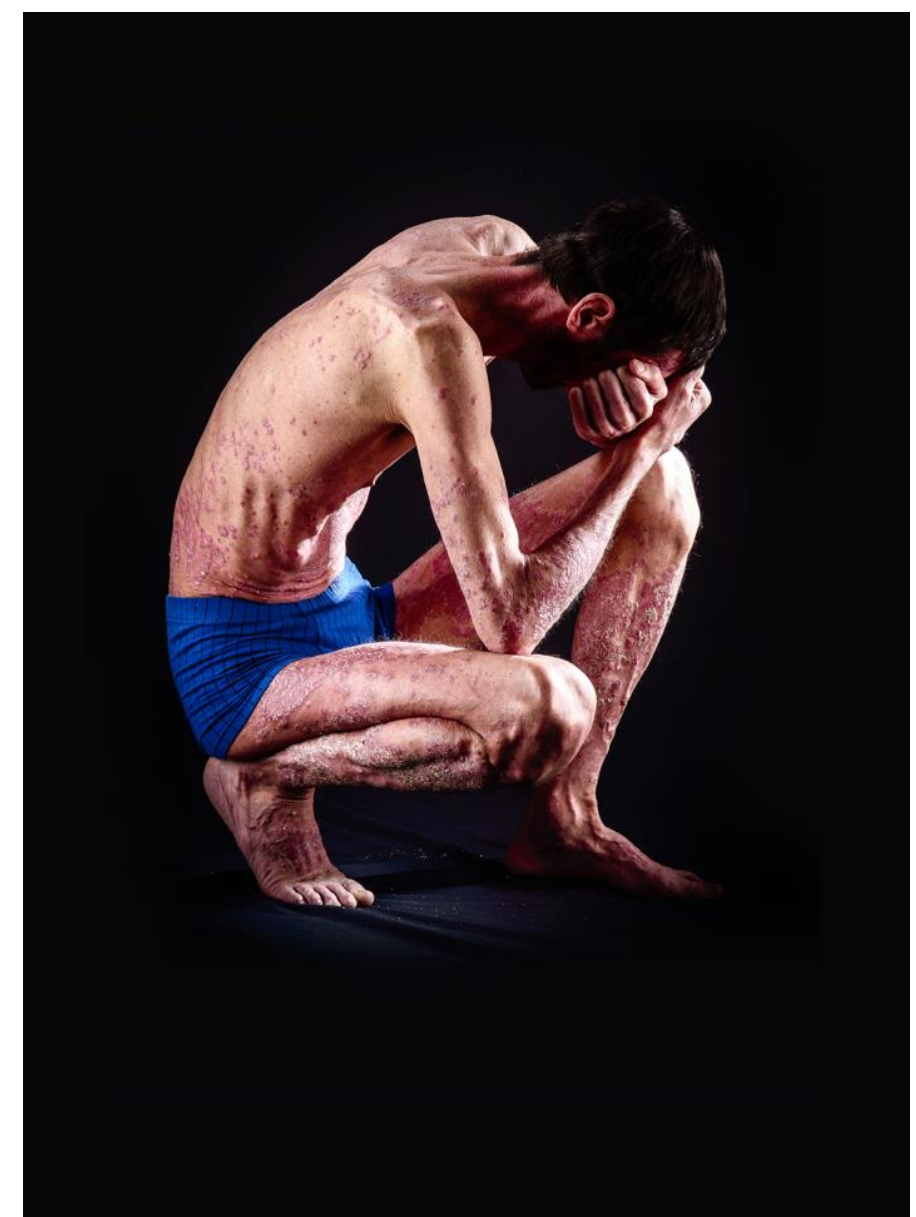

Fig. 1. 'Discouraged'. The patient is in a cachectic condition and in a cowering position. His head is inclined downward and is masked behind his arms. The skin on the entire body is covered with disseminated scaly plaques, predominantly on the elbows, lower legs, and lower back. Expressed emotions: the patient is anxious. He is afraid his anxiety will be visible on the picture. He expresses helplessness and has to overcome his shame in order to show his skin lesions. He is concerned about the fact that the photographs will be stored forever and may be viewed in the future. 


\section{Case Reports in Dermatology}

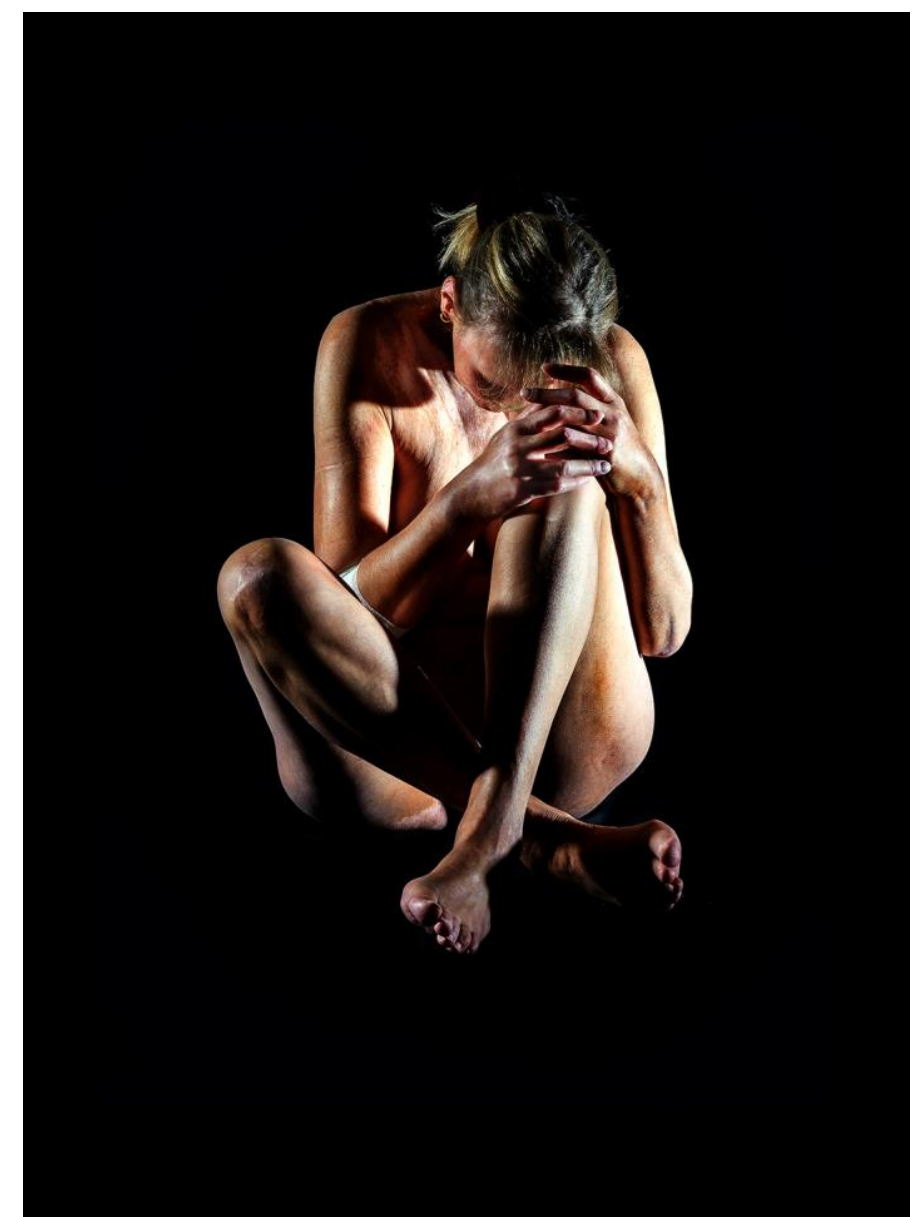

Fig. 2. 'Mourning'. The patient is in a fully cowering position, like an embryo, and hiding her face. The skin appears thickened and indurated; especially the fingers are red and thickened. Expressed emotions: the patient is happy to present her disease on a picture but tries to hide herself because of her hopelessness and despair. She knows her disease is progressing continuously but tries to overcome this by viewing her body in a picture series.

Aberer et al.: Medical Photography: Documentation, Art, and the Expression of Human Emotions 


\section{Case Reports in Dermatology}

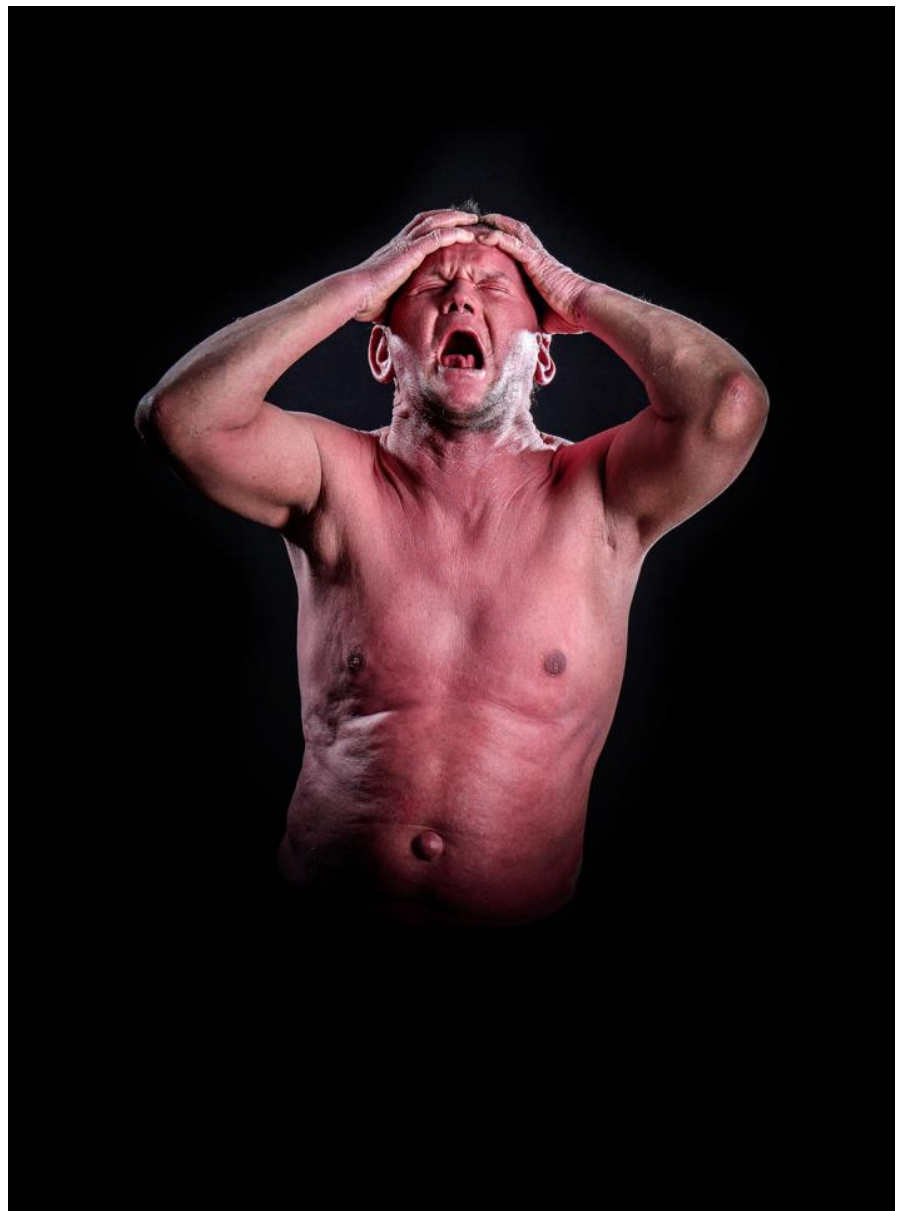

Fig. 3. 'The scream'. The patient's mouth is wide open. The eye area is contracted, with folds at the glabella. The arms are raised and the hands cover the forehead and ears. The skin is erythrodermic and scaled. Expressed emotions: the patient is anxious and upset. He says he would like to jump out of his skin and express his desperation in a loud voice - which, in fact, he did.

Aberer et al:: Medical Photography: Documentation, Art, and the Expression of Human Emotions 


\section{Case Reports in Dermatology}

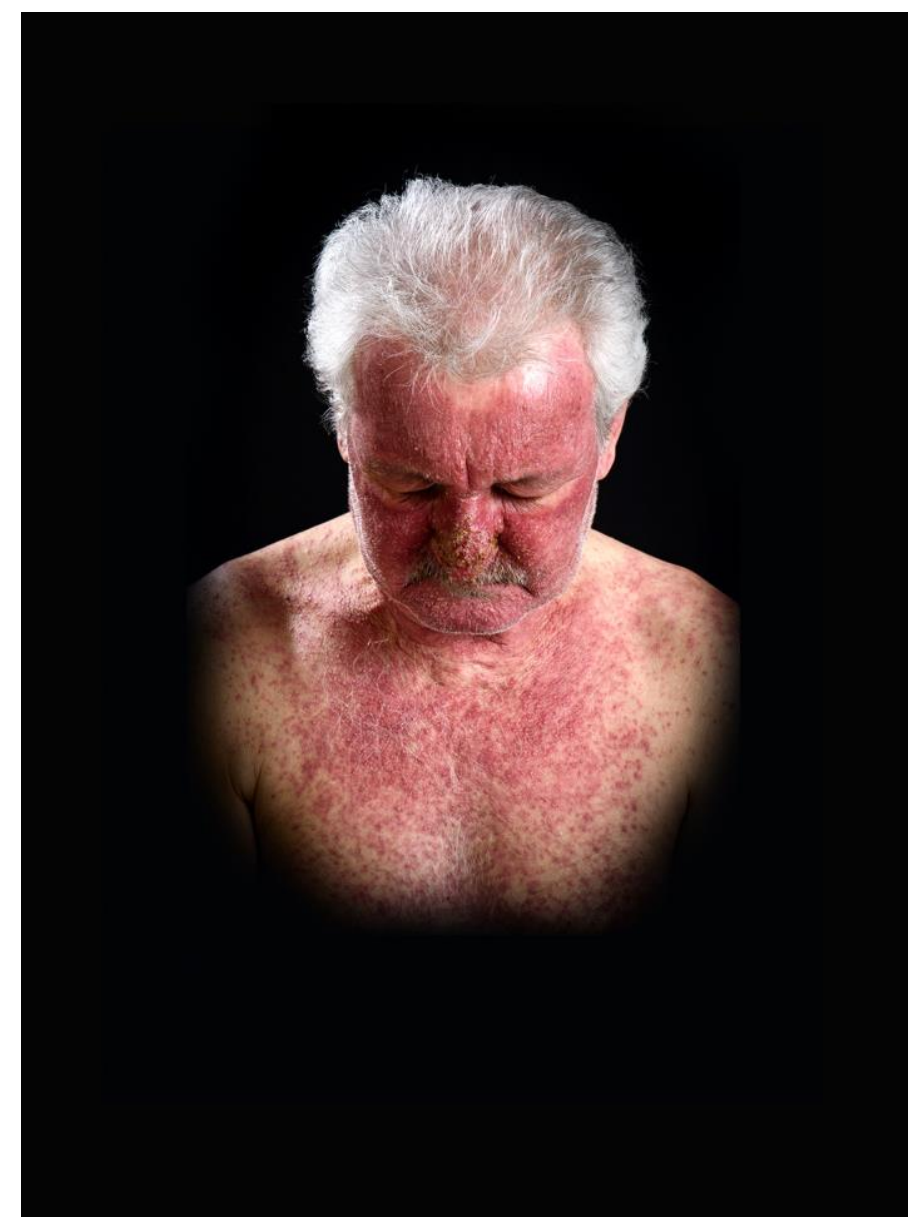

Fig. 4. 'Depression'. The patient stands with a bent head. The hanging corners of his mouth are barely visible and he does not look at the camera. His face has a deep red color, with papules and crusts on the nose. He has disseminated red papules on the upper trunk. Expressed emotions: the patient's basic mood is depressive. He is reserved, feels unwell, and feels he has to accept his fate. He is unable to look friendly.

Aberer et al.: Medical Photography: Documentation, Art, and the Expression of Human Emotions 


\section{Case Reports in Dermatology}

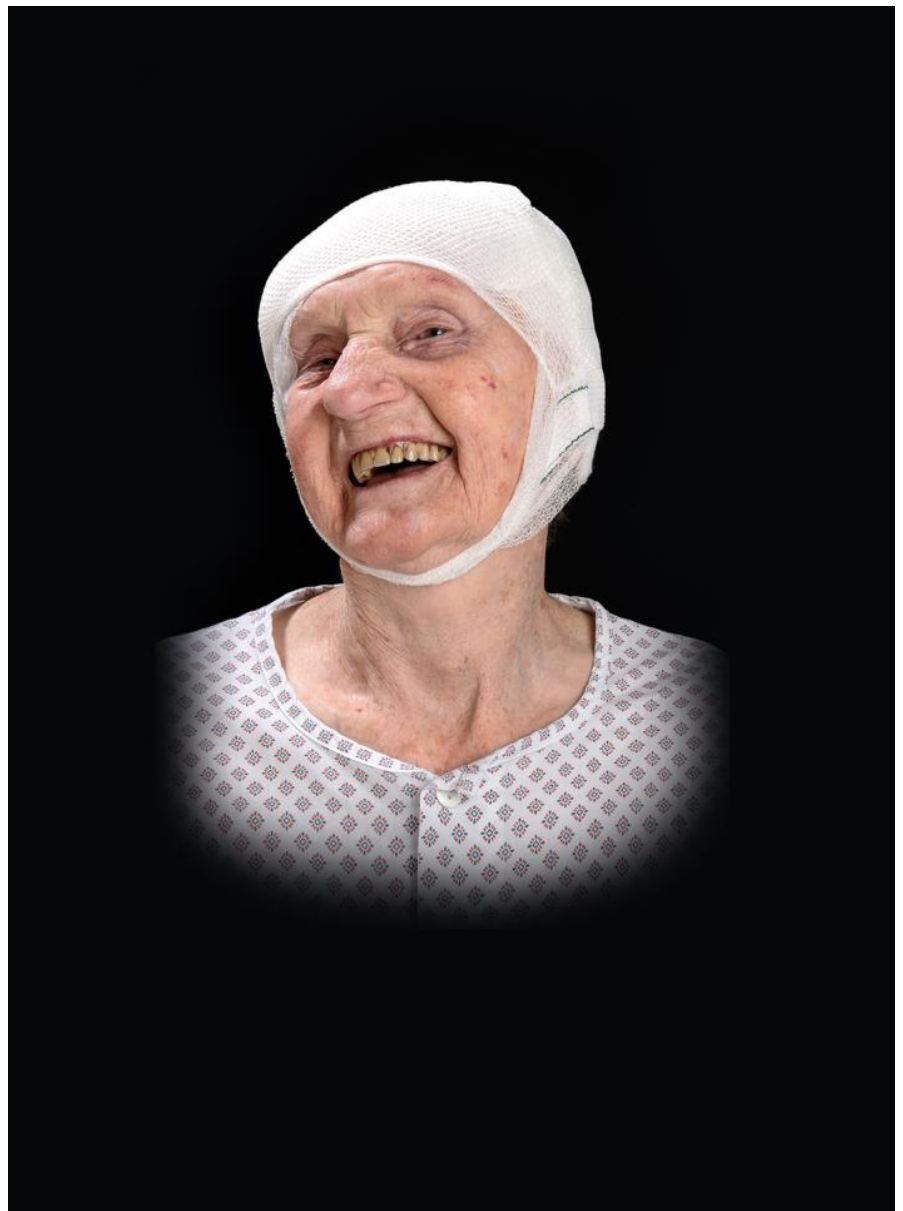

Fig. 5. 'Joie de vivre (joy of life)'. The photograph shows a laughing elderly woman. Her head is covered with a white cap. The remaining visible skin shows signs of aging. Expressed emotions: the patient looks happy and content. She receives attention because of her cap. She has overcome her operation, which was devoid of complications. Being an elderly woman, she finds it easy to be happy.

Aberer et al:: Medical Photography: Documentation, Art, and the Expression of Human Emotions 


\section{Case Reports in Dermatology}

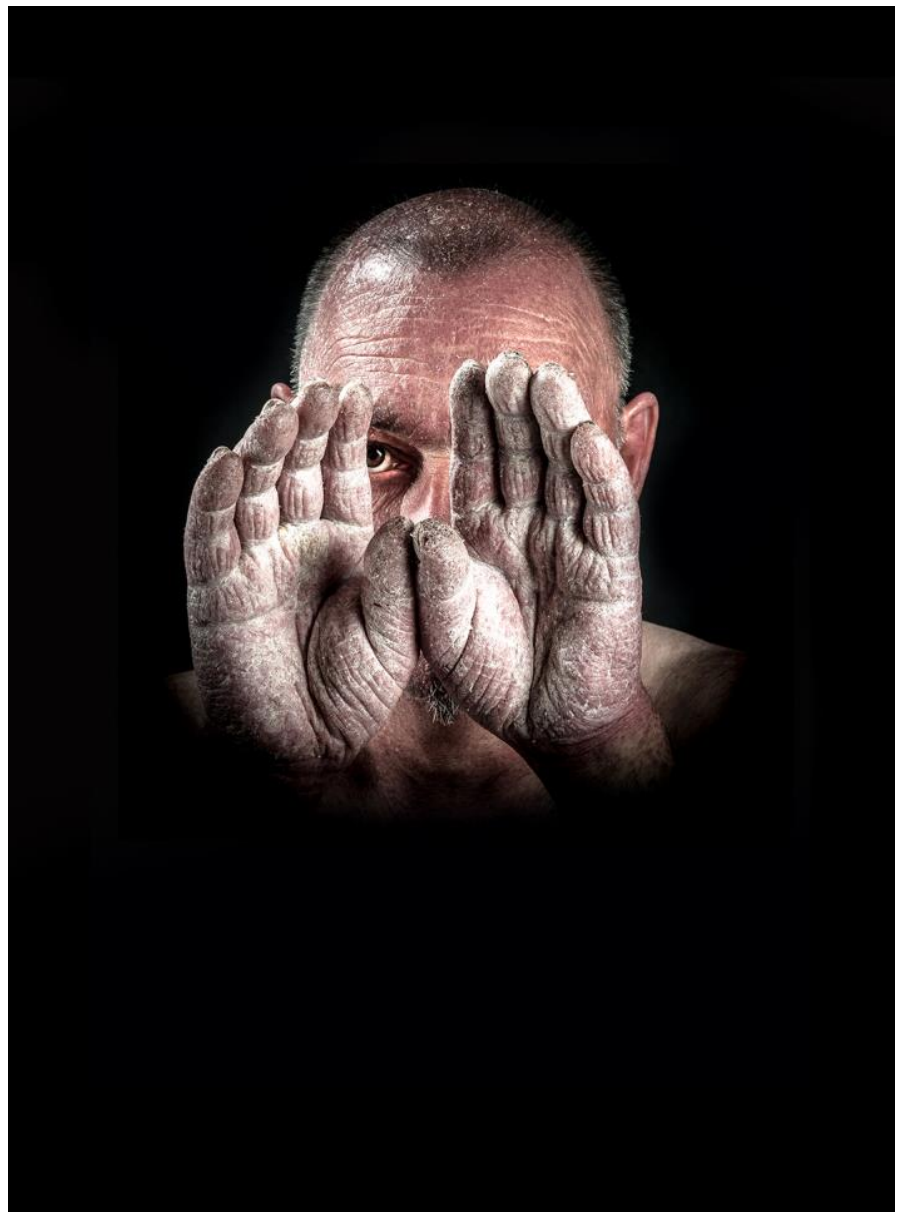

Fig. 6. 'Anxiety'. The patient holds both hands in front of his head, showing his palms, expressing a defensive attitude, protecting his face from the camera, and leaving just one eye to look through. The palms of his erythematous hands are covered with thick white scales and show deep and prominent skin folds. The parietal area of the head is red and covered with scales. Expressed emotions: on communicating with the patient, we find that he is reserved, anxious, and slow in opening up with others and coming to terms with the situation. He is told that the purpose of taking the picture is not to present him as a dermatologic exhibit but to draw attention to the debilitating effect of the skin disease and his personal plight. The patient feels isolated and does not wish to be seen in the public as an unusual human specimen. He is able to relieve his concerns by communicating about his anxiety. 